\title{
Pulmonology
}

\section{Melatonin in Treatment of Sleep Disorders in Elderly Patients with Chronic Obstructive Pulmonary Disease}

\author{
Lyubov N. Tsvetikova, PhD; Olga V. Goncharenko; Andrey V. Budnevsky, PhD, ScD; \\ Evgeniy S. Ovsyannikov, PhD*; Vladislav N. Belov, PhD, ScD; \\ Evgenia A. Kudashova, PhD; Yanina S. Shkatova \\ Voronezh State Medical University named after N. N. Burdenko \\ Voronezh, The Russian Federation
}

\begin{abstract}
Background: Chronic obstructive pulmonary disease (COPD) may frequently be complicated by sleep disorders, which worse quality of life and lead to other adverse consequences. The objective of the study was to analyze clinical course of the disease and quality of life in elderly patients with both COPD and sleep disorders.

Methods and Results: The study included 50 patients with moderate and severe COPD in age from 60 to 75 years (mean age, $66.12 \pm 0.76$ years). Patients were divided into 2 groups randomly. For patients in Group 1, $3 \mathrm{mg}$ of melatonin was prescribed orally 30-40 minutes before bedtime for 14 days on the background of standard COPD therapy. Patients of Group 2 received only standard COPD therapy. After 12 months of follow-up, the number of exacerbations and hospitalizations for COPD significantly decreased in Group 1: from $3.74 \pm 0.19$ to $1.91 \pm 0.20$ times a year $(\mathrm{P}=0.0000)$ and from $2.08 \pm 0.18$ to $1.35 \pm 0.18(\mathrm{P}=0.0046)$. In Group 2, the dynamics of these parameters was not statistically significant. In addition, along with the improvement of sleep quality in COPD patients during treatment with melatonin, both state and trait anxiety scores and depression level improved. In Group 1, SF-36 scores (PF, RP, BP, and GH) have also significantly improved.

Conclusion: Correction of sleep disorders by melatonin in elderly patients with COPD improved the effectiveness of COPD treatment, and reduced the frequency and duration of exacerbations and the number of outpatient visits and hospitalizations. (International Journal of Biomedicine. 2017;7(2):108-110.)
\end{abstract}

Key Words: chronic obstructive pulmonary disease $\bullet$ melatonin $\bullet$ quality of life $\bullet$ sleep disorder

\section{Abbreviations}

BP, bodily pain; COPD, chronic obstructive pulmonary disease; FEV1, forced expiratory volume in one second; FVC, forced vital capacity; FEF, forced expiratory flow; GH, general health; MH, mental health; PF, physical functioning; RP, role-physical; RE, role-emotional; SF, social functioning.

\section{Introduction}

Chronic obstructive pulmonary disease (COPD), being one of the most common chronic lung diseases, is a very important medical and social problem. COPD is currently the

*Corresponding author: Evgeniy S. Ovsyannikov, PhD. Department of faculty therapy, Voronezh State Medical University named after N.N. Burdenko.Voronezh, Russia. E-mail: ovses@, yandex.ru. fourth leading cause of death in the world ${ }^{(1)}$ but is projected to be the 3rd leading cause of death by 2020. (2-6) Pharmacologic therapy for COPD is used to reduce symptoms, reduce the frequency and severity of exacerbations, and improve exercise tolerance and health status. ${ }^{(2)}$ To date, there is no conclusive clinical trial evidence that any existing medications for COPD modify the long-term decline in lung function. . $2,7-11)^{2}$

COPD may frequently be complicated by sleep disorders, which worse quality of life and lead to other adverse consequences. 
The goals of treatment for COPD exacerbations are to minimize the negative impact of the current exacerbation and prevent the development of subsequent events. ${ }^{(12)}$ At the same time, sleep disorders that occur in every second or third patient in the older age group are not corrected by a standard therapy and, therefore, are one of the reasons that lead to worsening in a patient's condition and quality of life. ${ }^{(2,13-15)}$ Thus, it is especially important to develop algorithms for planning drug therapy in COPD patients with sleep disorders, which would lead to a correction of sleep disorders and improve quality of life in these patients.

In recent years, the use of melatonin (the hormone of the pineal gland) as a hypnotic agent has attracted a lot of attention. Melatonin plays a major role in control of circadian rhythm and sleep regulation and has other effects on the immune system, neuroprotection, and oxidant/antioxidant activity. ${ }^{(16)}$ The available experimental and clinical data allow use of melatonin in order to correct sleep disorders and as an adaptogen in disorders of the circadian rhythm. The undoubted advantage is the safety of melatonin and its antioxidant and light antidepressive effects. ${ }^{(17-21)}$ Thereby it is relevant to evaluate the clinical course of disease in elderly patients with COPD and sleep disorders during melatonin treatment and according to this newly acquired information to develop algorithms for treating such patients in order to get better results and improve their condition.

The objective of the study was to analyze clinical course of the disease and quality of life in elderly patients with both COPD and sleep disorders.

\section{Materials and Methods}

The study included 50 patients with moderate and severe COPD in age from 60 to 75 years (mean age, 66.12 \pm 0.76 years). The study was approved by local ethics committee. Written informed consent was obtained from each patient.

Patients were divided into 2 groups randomly: Group 1 (16 men and 4 women) and Group 2 (20 men and 10 women). The diagnosis of COPD was based on a) clinical symptoms (cough, sputum production, shortness of breath), b) a history of exposure to risk factors, and c) signs of airflow limitation on spirometry: a post-bronchodilator FEV1/FVC ratio $<70 \%$.

${ }^{(2)}$ For patients in Group 1, $3 \mathrm{mg}$ of melatonin was prescribed orally 30-40 minutes before bedtime for 14 days on the background of standard COPD therapy. Patients of Group 2 received only standard COPD therapy. Standard COPD therapy was conducted in accordance with the GOLD guidelines. ${ }^{(2)}$

We analyzed the frequency of COPD exacerbations that required a visit to a general practitioner and the frequency of hospitalizations. Psychological status evaluation was performed using the Spielberger State-Trait Anxiety Inventory and Zung Self-Rating Depression Scale. Sleep disorders were studied using sleep quality questionnaires. (PSQI). Quality of life was evaluated by an SF-36 questionnaire. ${ }^{(22,23)}$ Examinations were conducted at baseline and 12-month follow-up.

The statistical analysis was performed using the statistical software «STATISTICA 7» and STATGRAPHICS Plus 5.1. Data are shown as mean+SEM. The Mann-Whitney
(U Test) was used to compare the differences between the two independent groups. The Wilcoxon criterion was used to compare the differences between the paired samples. A probability value of $\mathrm{P}<0.05$ was considered statistically significant.

\section{Results and Discussion}

The number of exacerbations and hospitalizations for COPD in patients of Groups 1 and 2 at baseline of the study was comparable. After 12 months of follow-up, the number of exacerbations and hospitalizations for COPD significantly decreased in Group 1: from $3.74 \pm 0.19$ to $1.91 \pm 0.20$ times a year $(\mathrm{P}=0.0000)$ and from $2.08 \pm 0.18$ to $1.35 \pm 0.18(\mathrm{P}=0.0046)$ (Table 1). In Group 2, the dynamics of these parameters was not statistically significant.

Table 1.

Frequency of exacerbations and hospitalizations before and after treatment in COPD patients

\begin{tabular}{|l|c|c|c|c|}
\hline \multirow{2}{*}{ Variable } & \multicolumn{2}{c|}{ Group 1 } & \multicolumn{2}{c|}{ Group 2 } \\
\cline { 2 - 5 } & Before & After & Before & After \\
\hline Exacerbations & $3.74 \pm 0.19$ & $1.91 \pm 0.20 *$ & $3.60 \pm 0.20$ & $3.45 \pm 0.29$ \\
\hline Hospitalizations & $2.08 \pm 0.18$ & $1.35 \pm 0.18 *$ & $1.95 \pm 0.13$ & $1.75 \pm 0.13$ \\
\hline$*-P<0.05$
\end{tabular}

In addition, along with the improvement of sleep quality in COPD patients during treatment with melatonin, both state and trait anxiety scores and depression level improved, suggesting that the general mechanisms are the same in the development of anxiety, depression and sleep disorders in elderly patients with COPD (Table 2).

Table 2.

Psychological status of COPD patients before and after treatment

\begin{tabular}{|l|c|c|c|c|}
\hline \multirow{2}{*}{$\begin{array}{c}\text { Variable } \\
\text { (in points) }\end{array}$} & \multicolumn{2}{|c|}{ Group 1 } & \multicolumn{2}{c|}{ Group 2 } \\
\cline { 2 - 5 } & Before & After & Before & After \\
\hline State anxiety & $43.12 \pm 0.59$ & $37.51 \pm 0.45 *$ & $44.11 \pm 0.71$ & $42.48 \pm 0.66$ \\
\hline Trait anxiety & $44.87 \pm 0.42$ & $38.13 \pm 0.65 *$ & $43.91 \pm 0.62$ & $42.18 \pm 0.45$ \\
\hline Depression & $57.18 \pm 0.76$ & $49.42 \pm 0.81 *$ & $58.48 \pm 0.71$ & $56.53 \pm 0.78$ \\
\hline $\begin{array}{l}\text { Sleep quality } \\
\text { index }\end{array}$ & $28.12 \pm 0.43$ & $17.21 \pm 0.51 *$ & $29.12 \pm 0.43$ & $27.93 \pm 0.58$ \\
\hline
\end{tabular}

$*-P<0.05$

In Group 1, SF-36 scores (PF, RP, BP, and GH) have also significantly improved. At the same time, there were not any significant improvements in such domains of SF-36 scales as SF, RE, and MH (Table 3).

Clinically, melatonin has been studied and used for a wide variety of sleep disorders. ${ }^{(16,24-28)}$ Anxiolytic and antidepressant effects of melatonin are associated with its biorythmological and normalizing effects on sleep and on the level of endogenous peptides. Melatonin is not only a unique synchronizer of endogenous biological rhythms, but also to a certain extent is a tranquilizer. 
Table 3.

Dynamics of SF-36 scores in COPD patients during treatment

\begin{tabular}{|l|c|c|c|c|}
\hline \multirow{2}{*}{ Variable } & \multicolumn{2}{|c|}{ Group 1 } & \multicolumn{2}{c|}{ Group 2 } \\
\cline { 2 - 5 } & Before & After & Before & After \\
\hline RF & $54.6 \pm 3.32$ & $64.1 \pm 2.71^{*}$ & $53.2 \pm 3.45$ & $52.2 \pm 2.32$ \\
\hline RP & $28.9 \pm 5.66$ & $48.3 \pm 3.90^{*}$ & $29.4 \pm 5.09$ & $27.8 \pm 4.21$ \\
\hline BP & $49.7 \pm 2.40$ & $60.6 \pm 2.89^{*}$ & $48.1 \pm 2.65$ & $47.2 \pm 2.11$ \\
\hline GH & $43.3 \pm 2.46$ & $51.4 \pm 3.02^{*}$ & $44.2 \pm 2.72$ & $42.2 \pm 3.14$ \\
\hline VT & $50.4 \pm 2.62$ & $56.1 \pm 2.60$ & $50.4 \pm 2.62$ & $49.1 \pm 2.90$ \\
\hline SF & $65.2 \pm 3.69$ & $69.3 \pm 2.80$ & $65.2 \pm 3.69$ & $63.1 \pm 2.98$ \\
\hline RE & $36.9 \pm 7.25$ & $41.8 \pm 6.29$ & $36.9 \pm 7.25$ & $35.1 \pm 5.76$ \\
\hline MH & $52.5 \pm 3.36$ & $56.9 \pm 3.24$ & $51.2 \pm 3.16$ & $50.9 \pm 3.54$ \\
\hline
\end{tabular}

* $-P<0.05$

In conclusion, correction of sleep disorders by melatonin in elderly patients with COPD improved the effectiveness of COPD treatment, and reduced the frequency and duration of exacerbations and the number of outpatient visits and hospitalizations. The algorithm of treatment for COPD patients should include use of sleep quality questionnaires, which would allow increasing the efficiency of therapeutic and preventive measures and quality of life of patients in primary care.

\section{Competing Interests}

The authors declare that they have no competing interests.

\section{References}

1. Lozano R, Naghavi M, Foreman K, Lim S, Shibuya K, Aboyans V, et al. Global and regional mortality from 235 causes of death for 20 age groups in 1990 and 2010: a systematic analysis for the Global Burden of Disease Study 2010. Lancet. 2012;380(9859):2095-128. doi:10.1016/S0140-6736(12)61728-0. 2. Global Initiative for Chronic Obstructive Lung Disease (GOLD, 2017 REPORT). Available from: http://goldcopd.org/ 3. Gibson GJ, Loddenkemper R, Lundbäck B, Sibille Y. Respiratory health and disease in Europe: the new European Lung White Book. Eur Respir J. 2013;42(3):559-63.

4. Provotorov VM, Budnevskiı̌ AV, Semenkova GG, Shishkina ES. [Proinflammatory cytokines in combination of coronary heart disease and chronic obstructive pulmonary disease]. Klin Med (Mosk). 2015;93(2):5-9. [Article in Russian].

5. Budnevsky AV, Esaulenko IE, Ovsyannikov ES, Zhusina YG. [Anemias in chronic obstructive pulmonary disease]. Ter Arkh. 2016;88(3):96-9. [Article in Russian].

6. Budnevsky AV, Provotorov VM, Ul'yanova MI. [Chronic obstructive pulmonary disease and anemia: clinical manifestations and therapeutic strategy]. Klin Med (Mosk). 2016;94(9):677-83. [Article in Russian].

7. MilewskaA, Rysiak E, Zareba I, HolowniaA, Mroz RM. Costs of Treatment of Chronic Obstructive Pulmonary Disease. Adv Exp Med Biol. 2016;885:67-75. doi: 10.1007/5584_2015_199. 8. Blanchette CM, Gross NJ, Altman P. Rising Costs of COPD and the Potential for Maintenance Therapy to Slow the Trend. Am Health Drug Benefits. 2014;7(2):98-106.

9. Downs CA, Appel SJ. Chronic obstructive pulmonary disease: diagnosis and management. J Am Acad Nurse Pract. 2007;19(3):126-32.

10. Kozhevnikova SA, Budnevsky AV. [Features of the clinical course of chronic obstructive pulmonary disease and quality of life in patients with coexisting metabolic syndrome]. Kazan Med Zh. 2016, 97(5):681-686. doi: 10.17750/kmj2016681. [Article in Russian].

11. Budnevsky AV, Isaeva YV, Malysh EY, Kozhevnikova SA. [Pulmonary rehabilitation as an effective method for optimizing therapeutic and preventive measures in patients with chronic obstructive pulmonary disease concurrent with metabolic syndrome]. Ter Arkh. 2016;88(8):25-9. [Article in Russian].

12. Martinez FJ, Han MK, Flaherty K, Curtis J. Role of infection and antimicrobial therapy in acute exacerbations of chronic obstructive pulmonary disease. Expert Rev Anti Infect Ther. 2006;4(1):101-24.

13. Vgontzas AN. The diagnosis and treatment of chronic insomnia in adults. Sleep. 2005;28(9):1047-8.

14. Morin CM, Rodrigue S, Ivers H. Role of stress, arousal, and coping skills in primary insomnia. Psychosom Med. 2003;65(2):259-67.

15. Rezaie L, Khazaie H, Yazdani F. Exploration of the experience of living with chronic insomnia: A qualitative study. Sleep Sci. 2016;9(3):179-185. doi: 10.1016/j.slsci.2016.07.001.

16. J. Bellapart J, Boots R. Potential use of melatonin in sleep and delirium in the critically ill. Br J Anaesth. 2012;108(4):57280. doi: 10.1093/bja/aes035.

17. Zhdanova IV. Melatonin as a hypnotic: pro. Sleep Med Rev. 2005;9(1):51-65.

18. Garzon C, Guerrero JM, Aramburu O, Gusman T. Effect of melatonin administration on sleep, behavioral disorders and hypnotic drug discontinuation in the elderly: a randomized, double-blind, placebo-controlled study. Aging Clin Exp Res. 2009;21(1):38-42.

19. Reiter RJ, Tan DX, Mayo JC, Sainz RM, Leon J, Czarnocki Z. Melatonin as an antioxidant: biochemical mechanisms and pathophysiological implications in humans. Acta Biochim Pol. 2003;50(4):1129-46.

20. Cajochen C, Krauchi K, Wirz-Justice A. Role of melatonin in the regulation of human circadian rhythms and sleep. J Neuroendocrinol. 2003;15(4):432-7.

21. Budnevskiy AV, Tsvetikova LN, Ovsyannikov ES, Goncharenko OV. [A role of melatonin for occurrence of chronic obstructive pulmonary disease]. Russian Pulmonology. 2016;26(3):372-78. [Article in Russian]

22. Ware JE Jr, Sherbourne CD. The MOS 36-item short-form health survey (SF-36). I. Conceptual framework and item selection. Med Care. 1992;30(6):473-83.

23. Ware JE Jr . SF-36 Health survey update. Spine (Phila Pa 1976). 2000;25(24):3130-9.

24. Buscemi N, Vandermeer B, Hooton N, Pandya R, Tjosvold L, Hartling L, et al. Efficacy and safety of exogenous melatonin for secondary sleep disorders and sleep disorders accompanying sleep restriction: meta-analysis. BMJ. 2006; 332(7578):385-93

25. Brzezinski A, Vangel MG, Wurtman RJ, Norrie G, Zhdanova I, Ben-Shushan A, et al. Effects of exogenous melatonin on sleep: a meta-analysis. Sleep Med Rev. 2005;9(1):41-50.

26. Dahlitz M, Alvarez B, Vignau J, English J, Arendt J, Parkes JD. Delayed sleep phase syndrome response to melatonin. Lancet. 1991;337(8750):1121-4.

27. Shamir E, Laudon M, Barak Y, Anis Y, Rotenberg V, Elizur A, et al. Melatonin improves sleep quality of patients with chronic schizophrenia. J Clin Psychiatry. 2000;61(5):373-7. 28. Nunes DM, Mota RM, Machado MO, Pereira ED, Bruin VM, Bruin PF. Effect of melatonin administration on subjective sleep quality in chronic obstructive pulmonary disease. Braz J Med Biol Res. 2008;41(10):926-31. 